\title{
Investigating iron redox evolution using the mineral chemistry network analysis platform, dragon
}

\author{
ELI MOORE ${ }^{1}$, ALEXANDRA OSTROVERKHOVA ${ }^{2}$, \\ DANIEL HUMMER ${ }^{3}$, SHAUNNA MORRISON ${ }^{4}$ AND \\ STEPHANIE SPIELMAN ${ }^{1}$
}

${ }^{1}$ Rowan University

${ }^{2}$ Southern Illinois University Carbondale

${ }^{3}$ Southern Illinois University

${ }^{4}$ Geophysical Laboratory, Carnegie Institution for Science

Presenting Author: mooreek@rowan.edu

The flow of energy and elements between the geosphere and biosphere can be traced through the changing redox chemistry of Earth's surface. Deep-time trends in the mineral record, including mineral age and elemental composition, reveal a dynamic history of changing redox states and chemical speciation. We present a user-friendly exploratory network analysis platform called dragon (Deep-time Redox Analysis of the Geobiology Ontology Network) to facilitate investigation of the expanding redox chemical network preserved in the mineral record throughout Earth's history and beyond. The utility of dragon is demonstrated by showing that as oxygen became more central in the Fe mineral chemistry network, the number of combinations of high and low electronegativity elements increased in $\mathrm{Fe}$ minerals through time, thus illustrating the importance of oxygen in expanding the chemical diversity of $\mathrm{Fe}$ minerals and influencing the bioavailability of $\mathrm{Fe}$ in the environment. Dragon opens up many possibilities for the investigation chemical linkages between minerals and biology. 